\title{
EDITORIAL
}

\section{LA INVESTIGACIÓN EN EL PROCESO DE ACREDITACIÓN INSTITUCIONAL EN LA U.D.C.A}

\author{
Germán Anzola Montero \\ Rector
}

No se puede concebir una Universidad de calidad sin el ejercicio de sus funciones primordiales que constituye la investigación: ser sustantiva, asociada y complementada con la docencia y la extensión.

En conformidad con lo anterior, desde hace 18 meses hemos tomado las anteriores premisas como fundamento para la consecución de nuestro objetivo final, que es la Acreditación Institucional, la cual, amerita hacer una retrospección de nuestra actividad, durante los 30 años de existencia.

El año 1983, fue el año de la entonces Corporación Universitaria de Ciencias Agropecuarias y empezó a funcionar con los programas de Medicina Veterinaria y de Zootecnia, en las cuales, predominada la formación profesional (solamente docencia), aunque con las prácticas y las pasantías de los estudiantes, se hizo una proyección social y la parte investigativa, denominada "formativa", también tuvo injerencia con los cursos y los seminarios, que se practicaron y, desde luego, con el "Trabajo de Grado", que se estableció como requisito para que los estudiantes pudieran obtener el título de Médico Veterinario o de Zootecnista.

Sin embargo, solamente 1987 y con mayor fuerza en 1992, la Universidad, con el nombramiento de profesores de tiempo completo y con funciones académicas ampliamente reconocidas, emprendió seriamente la tarea de asumir la investigación con mayor ahínco. Para ello, se contó con la colaboración del Doctor Guillermo Mateus Valles (q.e.p.d.), quien recomendó una política que sentó las bases en materia de Ciencias Pecuarias y, como efecto de los primeros resultados, fue el primer Trabajo de Investigación, del estudiante Luis Ernesto Rodríguez Quenza, en el tema de Anemia Infecciosa Equina.

Para obtener este logro, se consiguió el respaldo del Consejo Directivo de la U.D.C.A, para que se garantizara la vinculación y la permanencia de docentes-investigadores y, desde entonces, con dicho concurso, se ha continuado con esta tradición, de apoyar las iniciativas de programas, de proyectos, de líneas y de grupos de investigación, creación de laboratorios y dotación de equipos.
De acuerdo con nuestra naturaleza, Misión y Proyecto Institucional, la U.D.C.A ha planteado políticas claras y un compromiso decidido con la investigación, a pesar de las múltiples dificultades que esta actividad demanda en recursos económicos, físicos y tecnológicos y a la misma difusión de resultados que comprende: publicaciones, patentes, registros, desarrollo tecnológico, premios y otros.

Como quiera es que la calidad de una Universidad está íntimamente asociada con la práctica de la investigación y no solamente se debe hacer investigación sino utilizarse pertinentemente en la docencia y en la extensión. La investigación se hace realidad si la misma está entrelazada con los procesos de formación, ya sea en el nivel universitario o en el de las maestrías (pronto con los doctorados). Todo esto lo arrojará el resultado del proceso de autoevaluación que venimos adelantando y que nos dejará ratificar en nuestro PEI, que la investigación es una función sustantiva, que nos permitirá alcanzar un nivel de desarrollo científico en bien de profesionales competentes, para que, a su vez, solucionen los grandes problemas que acogen a nuestra sociedad. $\mathrm{Si}$ por ahora no logramos alcanzar el reconocimiento de los estándares más altos de las universidades más desarrolladas del país, puedo afirmar que con nuestros planes de mejoramiento podremos lograr nuestra meta más codiciada, que no es otra que constituirnos como una universidad de excelencia.

No obstante, existen en Colombia grandes falencias en cuanto avanza la investigación científica: la drástica reducción de fondos, los recortes en convocatorias, la disminución de becas, la no renovación o compra de equipos, la falta de contratación de personal, algunas de ellas, por debilidad institucional, mayor inequidad, reducción en la competitividad o por fuga de cerebros. El columnista del Diario El Tiempo, Jorge Orlando Melo expresó que "Nos aprovechamos como buenos parásitos de la ciencia y la técnica universal, sin tener que gastar en desarrollarla pero al mismo tiempo sin adoptarla para lograr resultados óptimos" y más adelante "Ahora por principio, las universidades han puesto la investigación científica como parte de su 'Misión y su visión' y han definido medidas para calificar sus aportes. Estas mediciones, como la ciencia que practicamos, tiene que ver poco con los pro- 
blemas del país, cuentan ante todo gestos y movimientos: es un registro notarial de artículos, patentes o grupos de investigadores, pero sin que se sepa si lo que se publica o investiga sirve para algo, si hemos aportado nuevos conocimientos a la ciencia, si algo patentado funcionó".

Con todas estas críticas son las universidades las llamadas a formar profesionales idóneos y altamente calificados para dar respuesta a los desafíos, que en distintos campos, esta sociedad plantea. La investigación universitaria Colombiana, sin duda alguna, ha vivido cambios importantes en los últimos años y, por ello, las instituciones de educación superior están generando nuevo conocimiento, con el propósito de mejorar la calidad de vida de los ciudadanos. Por esto, la Universidad de Ciencias Aplicadas y Ambientales U.D.C.A, se debe comprometer con los siguientes principios frente a la función sustantiva de investigación e impulsar acciones investigativas hacia el futuro, con mayor decisión y coraje:

a. Definir los campos de investigación y las prioridades investigativas

b. Optimizar la calidad de la infraestructura investigativa, representada en laboratorios, en instrumentos, en recursos bibliográficos, en recursos informáticos

c. Implementar la calificación académica de los investigadores

d. Apoyar la creación y grado de desarrollo de grupos, de redes, de programas y de líneas de investigación

e. Brindar estabilidad a los grupos de investigación y a sus investigadores f. Dedicar el tiempo necesario para la investigación del personal académico y reconocido por la institución para tareas investigativas

g. Generar vínculos con pares nacionales e internacionales

h. Incentivar los tipos de publicaciones especializadas, según su carácter nacional o internacional y si están o no indexadas; citas y referencias en trabajos de investigación de la institución; patentes, registros, desarrollos tecnológicos; premios y distinciones por trabajos de investigación

i. Asignar presupuesto de investigación propio y consecución de financiación externa nacional o internacional

j. Establecer un grado de interdisciplinariedad de la investigación

k. Determinar la intensidad y continuidad de trabajos de campo

l. Crear e implementar el régimen de propiedad intelectual

Esta autoevaluación de la calidad con miras a la Acreditación Institucional implica una valoración sistémica de la Universidad, como un todo. Para ello, es necesario hacer un llamado a todos los estamentos que conforman la Comunidad Universitaria, para que adelantemos este proceso con todo el rigor, dinamismo y seriedad.

\section{Referencia bibliográfica:}

http://www.eltiempo.com/opinion/columnistas/jorgeorlandomelo/ARTICULO-WEB-NEW_NOTA_INTERIOR-12684530. html 